\title{
A Eficácia do Código de Defesa do Consumidor em Face do Tratamento Diferenciado aos Consumidores na Fase Pós-Venda, por Parte dos Serviços de Atendimento ao Consumidor
}

\author{
The Consumer Defense Code Efficacy Dacing the Differential Treatment of \\ the Consumers in the After Sales Phase by the Customer Support Services
}

\author{
Zaiden Geraige Neto \\ Universidade de Ribeirão Preto, Ribeirão Preto - SP, Brasil \\ Kerton Nascimento e Costa \\ Universidade de Ribeirão Preto, Ribeirão Preto - SP, Brasil
}

\begin{abstract}
Resumo: O presente trabalho pretende demonstrar a existência de um tratamento diferenciado entre os consumidores que são os alvos de ofertas e os consumidores que já compraram um produto ou contrataram serviços. Desde a diminuição dos canais de contato até a dificuldade de obter uma gravação telefônica dos atendimentos, o consumidor encontra imensas dificuldades na fase pós-venda, o que realça sua vulnerabilidade.
\end{abstract}

Palavras-chave: Consumidor. Diferenciação. Gravação de Conversas. Código de Defesa do Consumidor. Direitos Fundamentais. Pós-venda. Vulnerabilidade.
Abstract: The present essay aims to demonstrate the existence of different treatment related to consumers that are the target of the offers and consumers who have already purchased a product or contracted services. It also debates the decrease of the contact links that are offered to the consumers and the difficulty opposed to the consumer to obtain a recording of the phone calls, the consumers find great difficulties in the pos sale moment, which enhances their vulnerability.

Keywords: Consumer. Different Treatments. Phone Recorded Conversations. Code of Consumer Protection. Fundamental Rights. Pos Sale. Vulnerability.

Recebido em: 09/01/2015 Revisado em: 14/08/2015 Aprovado em: 09/09/2015 


\section{Introdução}

As figuras do consumidor e do fornecedor vêm sofrendo mudanças no decorrer da história. As relações de consumo evoluíram de verbais para verbais e contratuais, e hoje gravitam em torno, também, do mundo virtual, com seus contratos eletrônicos de adesão. O ciberespaço vem ganhando destaque e já há projeções de que em um futuro próximo as compras feitas pela internet superarão em muito, as compras feitas nas lojas físicas.

A sociedade, em constante mudança, festeja essa facilidade de acesso a ofertas realizadas nos mais longínquos lugares. Ofertas que enchem os olhos, esvaziam os bolsos e provocam, não raramente, "dores de cabeça" que se prolongam no tempo.

É ponto pacífico que o tratamento ao consumidor é diferente quando compra um produto ou serviço e quando necessita exercer seus direitos na fase pós-venda e na efetivação dos serviços contratados. Uma simples reclamação, ou uma tentativa de receber os valores envolvidos nas diversas espécies de seguros oferecidos aos consumidores, quando da ocorrência dos fatos contratados, não encontra a mesma acessibilidade dos canais de venda e oferecimento dos mesmos produtos e serviços.

Apesar de a hipossuficiência ser tutelada no Código de Defesa do Consumidor, produzir um mínimo de lastro probatório, até para que seja identificada a verossimilhança das alegações, é fundamental na sustentação ao pleito consumerista, o que se mostra dificultoso ante as artimanhas dos serviços de telemarketing passivos, a "disposição" dos consumidores.

As tentativas de obter as gravações das conversas que ocorrem durante os atendimentos, por exemplo, demonstram essa dificuldade na produção de provas.

Estas breves linhas pretendem demonstrar a evolução da sociedade e do alcance das ofertas pelos meios eletrônicos, além de expor as dificuldades encontradas pelos consumidores no exercício de seus direitos no momento pós-venda, e na materialização dos serviços contratados. 
Inegável o imenso avanço proporcionado pelo Código de Defesa do Consumidor, e o imprescindível papel do Poder Judiciário na defesa dos consumidores. Entretanto, existem casos em que essas afrontas à lei consumerista sequer chegam ao conhecimento do Estado Juiz, demonstrando que uma nova postura na defesa do consumidor deve ser adotada, possibilitando o alcance e a punição de fornecedores que se escondem nos emaranhados das redes de dados.

\section{A Sociedade em uma Economia Globalizada}

O termo globalização vem sendo empregado com frequência, motivo pelo qual se faz necessária uma breve explanação sobre a terminologia.

Globalização, segundo o entendimento majoritário, é o processo econômico, e também social, que integra os países e o as pessoas ao redor do mundo, possibilitando a troca de ideias, a realização de transações financeiras e contatos comerciais, além da difusão das múltiplas culturas que compõe o ser humano. Em tese, trata-se de uma redução na distância que separa os países e continentes.

Contudo, tal fenômeno não é recente, tendo como marco o processo iniciado com as chamadas "Grandes Navegações", ocorridas entre os séculos XV e XVI, proporcionando que os habitantes do continente europeu tivessem contato com diferentes países, estabelecendo relações de comércio, transmitindo e absorvendo cultura.

Com a queda do socialismo e a saturação dos mercados internos, as empresas conhecidas como multinacionais expandiram o seu alcance, por meio do barateamento dos preços e com a valiosa contribuição da internet, proporcionando aos consumidores um amplo leque de opções, que antes não existiam.

Essa globalização é a mesma que possibilita as empresas multinacionais utilizarem a mão de obra mais barata na produção de seus produtos, oriunda de países menos desenvolvidos, tornando-os mais competitivos. Não se adentrará no mérito dessa prática, no que tange às condições de trabalho nesses países, afinal, tal explanação tem o único objetivo de 
demonstrar a mudança de uma sociedade que hoje é capaz de comprar qualquer produto, em qualquer parte do mundo, utilizando a rede mundial de dados.

Será usado como exemplo dessa facilidade de acesso aos mais diversos produtos e serviços o MERCOSUL, que hoje é integrado por Brasil, Argentina, Uruguai e Venezuela, sendo que o Paraguai, integrante do bloco original, encontra-se suspenso.

O Mercado Comum do Sul instituiu uma zona aduaneira entre os países que o integram, possibilitando um livre comercio e uma política comercial comum.

Por meio dessa integração, a oferta de produtos oriundos dos países integrantes do bloco cresceu exponencialmente e são encontrados com facilidade produtos como os famosos vinhos chilenos, além de poder desfrutar da qualidade incontestável dos cortes bovinos argentinos e uruguaios.

Essa demonstração de facilidade de acesso é de suma importância no desenvolvimento deste trabalho, ao esclarecer que a sociedade mudou e que, apesar do consumidor ter ampliado o seu acesso a ofertas e produtos, possibilitando a aquisição dos mais variados itens, ainda há um despreparo do fornecedor para lidar com a fase pós-venda e do Estado, em alcançar os responsáveis em reparar os eventuais vícios ou defeitos nos produtos e serviços.

\section{O Amparo Constitucional aos Consumidores e sua Importân- cia para a Ordem Econômica}

A proteção aos consumidores integra os direitos fundamentais, positivados no art. $5^{\circ}$, especificamente no inciso XXXII da Constituição Federal: "XXXII - o Estado promoverá, na forma da lei, a defesa do consumidor" (BRASIL, 1988, art. 5).

Norma de eficácia limitada, que foi regulamentada com a edição da Lei n. 8.078/90, o Código de Defesa do Consumidor, que objetiva o equilíbrio nas relações de consumo, com uma legislação especial e a criação 
de órgãos no âmbito governamental, além do estímulo à sociedade na árdua e constante tarefa de disciplinar o mercado consumidor.

A Ordem Econômica, primordial para a manutenção do Estado, tem como um dos seus princípios a defesa do consumidor, como visto no artigo 170, inciso V, da Constituição Federal:

A ordem econômica, fundada na valorização do trabalho humano e na livre iniciativa, tem por fim assegurar a todos existência digna, conforme os ditames da justiça social, observados os seguintes princípios:

I - soberania nacional;

II - propriedade privada;

III - função social da propriedade;

IV - livre concorrência;

V - defesa do consumidor;

VI - defesa do meio ambiente, inclusive mediante tratamento diferenciado conforme o impacto ambiental dos produtos e serviços e de seus processos de elaboração e prestação;

VII - redução das desigualdades regionais e sociais;

VIII - busca do pleno emprego;

IX - tratamento favorecido para as empresas de pequeno porte constituídas sob as leis brasileiras e que tenham sua sede e administração no País. Parágrafo único. É assegurado a todos o livre exercício de qualquer atividade econômica, independentemente de autorização de órgãos públicos, salvo nos casos previstos em lei. (grifo nosso). (BRASIL, 1988, art. 170)

Tal princípio tem a finalidade e, portanto, a natureza teleológica de uma atuação eficiente e constante do Estado na tutela do consumidor, já que não há uma diferenciação hierárquica entre os princípios elencados no artigo 170, sendo a defesa do consumidor tão importante quanto à soberania nacional e a propriedade privada.

E não poderia ser diferente, pois os consumidores exercem papel de suma importância na circulação de riquezas, sendo indispensáveis para 
o crescimento do país, justificando tamanha proteção, com o reconhecimento de sua vulnerabilidade perante o fornecedor.

O Código de Defesa do Consumidor é o ápice desta proteção, e traz em seus artigos $4^{\circ}$ e $5^{\circ}$ as diretrizes na criação e implementação das políticas Estatais de defesa ao consumidor:

Art. $4^{\circ}$ A Política Nacional das Relações de Consumo tem por objetivo o atendimento das necessidades dos consumidores, o respeito à sua dignidade, saúde e segurança, a proteção de seus interesses econômicos, a melhoria da sua qualidade de vida, bem como a transparência e harmonia das relações de consumo [...]

Art. $5^{\circ}$ Para a execução da Política Nacional das Relações de Consumo, contará o poder público com os seguintes instrumentos, entre outros:

I - manutenção de assistência jurídica, integral e gratuita para o consumidor carente;

II - instituição de Promotorias de Justiça de Defesa do Consumidor, no âmbito do Ministério Público;

III - criação de delegacias de polícia especializadas no atendimento de consumidores vítimas de infrações penais de consumo;

IV - criação de Juizados Especiais de Pequenas Causas e Varas Especializadas para a solução de litígios de consumo;

$\mathrm{V}$ - concessão de estímulos à criação e desenvolvimento das Associações de Defesa do Consumidor. (BRASIL, 1990, art. $4^{\circ}-5^{\circ}$ )

Acerca da redação do artigo $4^{\circ}$, apresenta-se o entendimento de Claudia Lima Marques (2013, p. 227), que classifica as normas existentes no artigo como "normas narrativas", que funcionam como princípios para as demais normas consumeristas:

As normas "narrativas", como o art. $4^{\circ}$, são usadas para interpretar e guiar, melhor dizendo, "iluminar" todas as outras normas do microssistema. Elas aplicam-se como inspiração, guia, teleologia, indicando o caminho, o objetivo, como afirmou Eros Roberto Grau criando a expressão "norma-objetivo". 
A Política Nacional das Relações de Consumo, prevista no artigo $5^{\circ}$, um conjunto de objetivos a serem alcançados pelo Estado, é a clara amostra da imprescindibilidade da figura do consumidor, atestando sua importância na geração de riquezas e manutenção da Ordem Econômica. Diante de tamanha importância, ganha destaque a intervenção estatal, na persecução do objetivo político de proteção dos consumidores (MARQUES, 2013).

A autora elenca um considerável aumento nas intervenções do Estado nas relações contratuais, nos anos de 1980 e 1990, no "[...] intuito de relativizar o antigo dogma da autonomia da vontade com as novas preocupações de ordem social e com a imposição de um novo paradigma, o princípio da boa fé objetiva" (MARQUES, 2013, p. 264).

Diante do importante papel do consumo, o instrumento legislativo tece as minúcias, elencando, em um rol exemplificativo, os direitos básicos do consumidor:

São direitos básicos do consumidor:

I - a proteção da vida, saúde e segurança contra os riscos provocados por práticas no fornecimento de produtos e serviços considerados perigosos ou nocivos;

II - a educação e divulgação sobre o consumo adequado dos produtos e serviços, asseguradas a liberdade de escolha e a igualdade nas contratações;

III - a informação adequada e clara sobre os diferentes produtos e serviços, com especificação correta de quantidade, características, composição, qualidade e preço, bem como sobre os riscos que apresentem;

IV - a proteção contra a publicidade enganosa e abusiva, métodos comerciais coercitivos ou desleais, bem como contra práticas e cláusulas abusivas ou impostas no fornecimento de produtos e serviços;

V - a modificação das cláusulas contratuais que estabeleçam prestações desproporcionais ou sua revisão em razão de fatos supervenientes que as tornem excessivamente onerosas; 
VI - a efetiva prevenção e reparação de danos patrimoniais e morais, individuais, coletivos e difusos;

VII - o acesso aos órgãos judiciários e administrativos com vistas à prevenção ou reparação de danos patrimoniais e morais, individuais, coletivos ou difusos, assegurada a proteção Jurídica, administrativa e técnica aos necessitados;

VIII - a facilitação da defesa de seus direitos, inclusive com a inversão do ônus da prova, a seu favor, no processo civil, quando, a critério do juiz, for verossímil a alegação ou quando for ele hipossuficiente, segundo as regras ordinárias de experiências;

IX - (Vetado);

$\mathrm{X}$ - a adequada e eficaz prestação dos serviços públicos em geral. (grifo nosso). (BRASIL 1990, art. $6^{\circ}$ )

Consumir está ligado à Dignidade, e busca-se nas palavras de Luis Roberto Barroso (2000, p. 296), a amplitude de tal ideal, pois “[...] passar fome, dormir ao relento, não conseguir emprego, são, por certo, situações ofensivas à dignidade humana".

Sobre o tema, e por derradeiro, faz-se uso das ideias de Ingo Wolfgang Sarlet (2001, p. 301), já que “[...] proteção à dignidade da pessoa humana é norma fundamental, voltada a garantir faculdades jurídicas necessárias à existência humana".

\section{O Fornecedor Diferenciando o Atendimento nos Serviços de Venda e Pós-venda}

Quem nunca se deparou com um atendimento diferente quando compra um produto e quando precisa sanar um vício ou defeito?

Quem nunca se deparou com atendimento de telemarketing que não resolve o seu problema e, quando o consumidor solicita falar com um responsável, diante da falta de solução oferecida pelo primeiro atendimento, tem sua chamada desconectada?

Quem nunca se deparou com aquela mensagem que diz que sua ligação será ou poderá ser gravada, e quando necessita utilizar essa grava- 
ção para provar o que contratou (ou não contratou), e até comprovar um mau atendimento, simplesmente não consegue?

Questões que certamente atormentam diversos consumidores e assoberbam as pautas dos serviços de proteção ao consumidor pelo país afora.

Acerca do tema, e como mostra da problemática, será trazida para discussão a Lei do Serviço de Atendimento ao Consumidor (SAC), ou o Decreto n. 6.523, de 31 de julho de 2008, que veio para regulamentar o $\mathrm{CDC}$, vindo a fixar normas gerais sobre o serviço de atendimento ao consumidor.

Tal decreto nasceu ante a enorme gama de reclamações oriundas dos serviços prestados por operadoras de telemarketing. É possível observar o que diz a redação do artigo $2^{\circ}$ do aludido dispositivo legal:

Para os fins deste Decreto, compreende-se por SAC o serviço de atendimento telefônico das prestadoras de serviços regulados que tenham como finalidade resolver as demandas dos consumidores sobre informação, dúvida, reclamação, suspensão ou cancelamento de contratos e de serviços.

Parágrafo único. Excluem-se do âmbito de aplicação deste Decreto a oferta e a contratação de produtos e serviços realizadas por telefone. (BRASIL, 2008, art. $2^{\circ}$, grifo nosso)

Notem que o parágrafo único trás à tona o cerne da questão, em uma clara demonstração de que há sim uma diferenciação entre os serviços de telemarketing que promovem a oferta e a contratação, e os canais de atendimento que objetivam resolver as demandas dos consumidores na fase pós-venda.

Então, após "conquistar" o cliente, o tratamento muda, e se torna extremamente dificultoso fazer valer os direitos previstos nos contratos assinados, em regra de adesão, ou virtuais, estes sempre de adesão.

Apesar de a produção de prova ser um ponto crucial nessa questão, o CDC prevê a inversão do ônus da prova, a critério do juiz, segundo as 
regras gerais de experiência, a verossimilhança das alegações, e quando a hipossuficiência do consumidor restar comprovada (BRASIL, 1990).

Texto que gera uma divergência, pois a letra da lei pode transmitir a errada impressão de que a inversão é ato discricionário do juiz. Presentes um dos dois requisitos, ou seja, verossimilhança das alegações ou hipossuficiência do consumidor cabe ao magistrado inverter o ônus da prova.

Sobre o assunto, Rizzato Nunes (2009, p. 773, grifo nosso) esclarece que:

[...] apenas se presentes um destes casos é que ao juiz cabe inverter o ônus da prova, por isso a expressão "a critério do juiz" não designa discricionariedade ou subjetividade e sim aquilo que serve de base de comparação.

E complementa:

[...] para fins de inversão do ônus da prova, tem sentido de desconhecimento técnico e informativo do produto e do serviço, de suas propriedades, de seu funcionamento vital e/ou intrínseco, de sua distribuição, dos modos especiais de controle, dos aspectos que podem ter gerado o acidente de consumo e o dano, das características do vício etc. (NUNES, 2009, p. 775)

Enfim, a hipossuficiência não pode ser confundida com falta de recursos financeiros, pois ela está ligada a falta de conhecimento técnico, sendo esta a limitação que o legislador buscou equilibrar.

Rizzato Nunes (2009, p. 130, grifo nosso) também define a posição diferente entre os fornecedores e consumidores, pois “[...] é o fornecedor que escolhe o que, quanto e de que maneira produzir, de sorte que o consumidor está à mercê daquilo que é produzido".

Resta comentar sobre a divergência doutrinária que afeta a inversão do ônus da prova, ou seja, o momento processual de sua aplicação. Há doutrinadores que entendem ser o momento ideal entre o pedido inicial e a decisão saneadora, outros no julgamento. A falta de clareza no texto legal, quanto ao momento em que deve ocorrer a inversão, gera a controvérsia. 
Em que pese a importância da discussão, o posicionamento majoritário é de que o momento oportuno é na audiência de instrução e julgamento, após a constatação da existência dos requisitos (verossimilhança das alegações ou hipossuficiência), permitindo que a parte adversa se defenda.

Esclarecidos os pontos divergentes, será demonstrado o quão importante é a facilitação da defesa do consumidor, por meio da inversão do ônus da prova, como pode ser comprovado no julgamento de um recurso de apelação pelo Tribunal de Justiça de São Paulo:

\section{Apelação Cível n.: 0040909-92.2007.8.26.0114 (990.10.399072-2)}

Pois bem. Não há dúvida de que o contrato foi inicialmente celebrado de forma verbal, prática comum no mercado de assinatura de jornais e revistas. No entanto, comumente, os serviços de telemarketing mantêm registro da conversa telefônica, justamente para demonstrar que o consumidor foi cientificado de todos os termos e condições do contrato.

Dentro dessa linha de raciocínio, realmente o autor não pode fazer prova desse fato, ou seja, de que autorizou verbalmente a assinatura com renovações automáticas até pedido de encerramento. Essa hipossuficiência técnica autoriza a inversão do ônus da prova. (SÃO PAULO, 2010, grifo nosso)

O julgamento acima mencionado atesta que a ausência do arquivo de áudio e a consequente impossibilidade de provar o que foi acordado em um atendimento telefônico, não configura obstáculo para que o Judiciário atue, sendo a inversão do ônus da prova uma ferramenta eficaz na garantia dos direitos dos consumidores.

Uma questão que também merece destaque é a diferenciação entre vício e defeito.

Um produto ou serviço é defeituoso quando não apresenta a segurança que dele se espera, conforme a redação dos parágrafos $1^{\circ}$ dos artigos 12 e 13 do CDC: 
$\S 1^{\circ} \mathrm{O}$ produto é defeituoso quando não oferece a segurança que dele legitimamente se espera, levando-se em consideração as circunstâncias relevantes [...].

$\S 1^{\circ} \mathrm{O}$ serviço é defeituoso quando não fornece a segurança que o consumidor dele pode esperar, levando-se em consideração as circunstâncias relevantes [...]. (BRASIL, 1990, art. 12-13)

Um produto ou serviço está eivado de vício quando há disparidade entre a quantidade, qualidade ou mesmo em relação à oferta, de acordo com os arts. 18 e 20 do CDC:

Art. 18 Os fornecedores de produtos de consumo duráveis ou não duráveis respondem solidariamente pelos vícios de qualidade ou quantidade que os tornem impróprios ou inadequados ao consumo a que se destinam ou lhes diminuam o valor, assim como por aqueles decorrentes da disparidade, com as indicações constantes do recipiente, da embalagem, rotulagem ou mensagem publicitária, respeitadas as variações decorrentes de sua natureza, podendo o consumidor exigir a substituição das partes viciadas. (grifo nosso) Art. $20 \mathrm{O}$ fornecedor de serviços responde pelos vícios de qualidade que os tornem impróprios ao consumo ou thes diminuam o valor, assim como por aqueles decorrentes da disparidade com as indicações constantes da oferta ou mensagem publicitária [...]. (BRASIL, 1990, art. 18 e 20, grifo nosso)

Esclarecida a diferença, tratar-se-á da dificuldade do consumidor na produção de provas, em especial quando o atendimento se dá por meio de contato telefônico, com as consequentes, ou não, gravações das conversas.

\section{A Dificuldade do Consumidor na Produção de Prova}

É fato inconteste que o sucesso de uma demanda levada a apreciação do Poder Judiciário, em sua grande maioria, depende de uma eficiente e lícita produção de provas.

Sobre tal assunto, é possível observar as palavras de Marcos Vinícius Rios Gonçalves (2012, p. 408, grifo nosso): 
Mas o mais comum é que, para julgar, o juiz precisa examinar a veracidade dos fatos que, no curso do processo, tenham se tornado controvertidos. Para isso, será indispensável que ele analise as provas produzidas no processo, que visam demonstrar a veracidade dos fatos alegados pelas partes. É por meio das atividades probatórias que o juiz terá elementos para decidir sobre a veracidade e a credibilidade das alegações.

Contudo, quando se trata de provar a ocorrência de um atendimento insatisfatório ou mesmo uma divergência entre o teor do contrato e o que está efetivamente sendo fornecido, isso se mostra deveras dificultoso para o vulnerável consumidor.

Os canais de atendimento disponibilizados pelos fornecedores na fase pós-venda ou na tentativa de sanar os eventuais vícios nos produtos e serviços, não são tão amplos como os disponíveis na conquista do cliente.

Outra questão importante é a respeito das gravações das conversas entre consumidores e fornecedores. Apesar de receber no início do atendimento a informação de que a gravação poderá ser efetuada e estará à disposição do consumidor, a realidade é bem diferente.

Reportagem veiculada na versão eletrônica do Estadão, no blog "Advogado de Defesa", dia 18 de Outubro de 2010, ilustra bem essa dificuldade:

No dia $1^{\circ}$ de dezembro de 2008 entrou em vigor a Lei do SAC, que regulamenta o atendimento ao cliente prestado pelas empresas e que estabeleceu normas para melhorar o atendimento, entre elas a obrigatoriedade da liberação das gravações assim que o cliente pedir. As empresas são obrigadas a armazenar esses arquivos por, no mínimo, 90 dias. (JORNAL DA TARDE, 2010)

Apesar da chamada Lei do SAC, o Decreto n. 6.523, de 31 de julho de 2008, os problemas certamente persistem. Até para a elaboração deste artigo fica difícil comprovar a existência de tais práticas. Os atendimentos a consumidores por telefone, não raramente, disponibilizam canais de comunicação, que, em tese, teriam a função de sanar os problemas decor- 
rentes da relação de consumo, de vícios ou defeitos, ou mesmo do mau uso dos produtos e serviços. Ocorre que tais canais apresentam informações do tipo, "essa ligação poderá ser gravada, para uso exclusivo da empresa", ou a "gravação poderá ser solicitada, caso seja necessário".

Parece haver uma inversão dos papeis na relação de consumo, onde a "vítima" do mau atendimento, que poderá utilizar a gravação como meio de prova, seria a empresa e não o consumidor, que busca a solução do defeito ou vício em um produto ou serviço prestado.

Diante de tal situação, fica evidente a vulnerabilidade do consumidor, e também o esforço do Executivo na edição de um Decreto que diferencia o momento pós-venda do serviço de oferta e contratação de produtos e serviços.

Contudo, a exemplo desse "serviço" de atendimento, colocado à disposição do consumidor, e da tentativa de regulamentar os canais de atendimento denominados SAC (Serviço de Atendimento ao Cliente), parece não existir, por parte dos fornecedores, boa vontade e interesse na melhoria do atendimento prestado, pois as práticas continuam a desrespeitar a legislação consumerista.

Fato que certamente é estimulado pela desistência do consumidor, ante as inúmeras tentativas frustradas na resolução das questões pendentes.

Sobre a problemática, a reportagem traz um depoimento que reflete a realidade dos consumidores:

O motoboy Anderson Silvio Caetano, 27, ficou dois meses solicitando a Telefônica a gravação da sua conversa com um atendente que vendeu o plano errado a ele. O tempo de espera e a falta de solução motivaram o cliente a desistir do arquivo. (JORNAL DA TARDE, 2010)

Empresas chegam a afirmar que somente disponibilizarão as gravações das conversas mediante ordem judicial, desrespeitando claramente a determinação legal e levando questões ao Judiciário que deveriam ser resolvidas naturalmente pelos canais colocados a disposição do consumidor. 
É direito do consumidor o acesso às gravações, e não um favor, ou um "mimo gracioso" dos fornecedores. Veja-se o entendimento do Tribunal de Justiça de Minas Gerais, por meio de um AI julgado em 3 de maio de 2013, que deferiu a inversão do ônus da prova, face a evidente hipossuficiência do consumidor, que neste caso é uma pessoa jurídica de capital diminuto, se comparado a uma operadora de telefônica celular.

\begin{abstract}
AI $10024130293236001 \mathrm{MG}$
PROCESSUAL CIVIL - CONTRATO DE PRESTAÇÃO DE SERVIÇOS - TELEFONIA MÓVEL - GRAVAÇÕES TELEFÔNICAS - ÔNUS DA PROVA - INVERSÃO.

À relação jurídica decorrente de contrato de prestação de serviços, celebrado entre pessoa jurídica de capital diminuto e operadora de telefonia celular, diante da inegável hipossuficiência de uma em relação à outra, bem como na hipossuficiência técnica para a produção de prova relevante ao julgamento, aplicam-se as normas do Código de Defesa do Consumidor, deferindo-se, por conseguinte, o pedido de inversão do ônus da prova. (MINAS GERAIS, 2013)
\end{abstract}

A necessidade das constantes intervenções judiciais nas questões relativas aos atendimentos de telemarketing é prova inconteste de que uma nova postura precisa ser adotada, e que essa "tática" de vencer o consumidor pelo cansaço deve ser banida.

\title{
6 Conclusão
}

A evidente evolução e modificação nas figuras do fornecedor e, principalmente do consumidor, não retiraram sua importância e essencialidade na manutenção do Estado. Ao contrário, pois hoje o consumidor galga os mais altos postos, no que tange a tutela de seus direitos. Contudo, diferente se mostra a realidade compreendida entre o campo do dever, que se encontra positivada nos textos legais, e o campo do ser, que abrange a realidade enfrentada pelos consumidores, que buscam um atendimento condizente com a dignidade que lhe é inerente como pessoa humana. 
Consumidores que são desrespeitados, e que se veem forçados a buscar no Poder Judiciário a solução para conflitos que poderiam facilmente ser resolvidos no âmbito administrativo dos fornecedores de produtos e serviços; que são bombardeados por ofertas, das mais diversas e muitas vezes enganosas, e quando precisam fazer valer seus direitos são impedidos, ante a dificuldade de se formar um polo passivo, diante da ausência ou da impossibilidade de identificar os responsáveis pelo fornecimento dos produtos ou serviços oferecidos e contratados; e que contratam por adesão, por meio telefônico ou internet, e que tem imensa dificuldade de provar o que contrataram.

Por todo o exposto, é possível afirmar que, apesar da notável evolução na tutela do consumidor, de uma legislação minuciosa e digna de elogios, sendo considerada como um dos melhores sistemas de proteção ao consumidor no mundo, ainda resta um caminho a ser trilhado no combate às práticas de fornecedores que insistem em contar com a ignorância e a falta de tempo dos consumidores na busca pelos seus direitos.

O ideal da dignidade da pessoa humana, um dos fundamentos do Estado Democrático de Direito, vai além de um tratamento digno nas esferas da saúde, moradia, e o respeito à integridade física do cidadão. Tal dignidade está inserida no âmago do exercício da cidadania, onde uma natural e histórica evolução nos trouxe a usufruir um status ativo nos direitos fundamentais, participando efetivamente da construção de uma sociedade mais justa e fraternal.

Por óbvio que uma sociedade sem conflitos é uma utopia, porém, o respeito aos direitos do consumidor é um grande passo na diminuição das demandas levadas à apreciação do Poder Judiciário e, consequentemente, um amadurecimento no sentido da cidadania.

\section{Referências}

BARROSO, Luís Roberto. O Direito Constitucional e a efetividade de suas normas. 4. ed. Rio de Janeiro: Renovar, 2000. 
BRASIL. Constituição da República Federativa do Brasil de 1988. Brasília, DF: Senado Federal, 1988. Disponível em: <http://www. planalto.gov.br/ccivil_03/leis/L8078.htm>. Acesso em: $1^{\circ}$ fev. 2013.

. Lei n. 8.078, de 11 de setembro de 1990. [1990]. Disponível em: <http://www.planalto.gov.br/ccivil_03/leis/L8078.htm>. Acesso em: $1^{\circ}$ fev. 2013.

. Decreto n. 6.523, de 31 de julho de 2008. [2008]. Disponível em: <http://www.planalto.gov.br/ccivil_03/_ato2007-2010/2008/decreto/ d6523.htm>. Acesso em: 28 jan. 2013.

. Tribunal de Justiça de Minas Gerais. TJMG. AI

10024130293236001 MG 18. CÂMARA CÍVEL, em 30 de abril de 2013. Disponível em: <http://tj-mg.jusbrasil.com.br/jurisprudencia/115399901/ agravo-de-instrumento-cv-ai-10024130293236001-mg>. Acesso em: 3 nov. 2014

FILOMENO, José Geraldo Brito. Manual de direitos do consumidor. 3. ed. São Paulo: Atlas. 2008.

GONÇALVES, Marcos Vinícius Rios. Novo Curso de Direito Processual Civil: teoria geral e processo de conhecimento. 1. parte. 9. ed. São Paulo: Saraiva. 2012.

MARQUES, Claudia Lima; BENJAMIM, Antonio Herman V.; MIRAGEM, Bruno. Comentários ao Código de Defesa do Consumidor. 4. ed. ver. Atual., e ampl. São Paulo: Editora Revista dos Tribunais, 2013.

NUNES, Luis Antônio Rizzato. Curso de Direito do Consumidor. 4. ed. São Paulo: Saraiva, 2009.

SARLET, Ingo Wolfgang. A Eficácia dos Direitos Fundamentais. Porto Alegre: Livraria do Advogado, 2001.

SÃO PAULO. Tribunal de Justiça de São Paulo. TJSP Apelação n. Apelação Cível n. 0040909-92.2007.8.26.0114 (990.10.399072-2). 12. Câmara de Direito Privado, SP, 3 de outubro de 2010. Disponível em: $<$ https://esaj.tjsp.jus.br/cjsg/getArquivo.do?cdAcordao=6247354\&vlCapt cha=zbwks $>$. Acesso em: 13 fev. 2013. 
Zaiden Geraige Neto é doutor e mestre em Direito pela PUC/SP, professor de Direito do Mestrado da UNAERP, professor convidado do curso presencial de pós-graduação lato sensu em Direito Processual Civil da Faculdade de Direito da USP - Ribeirão Preto (FDRP/USP) e em MBA Executivo pela FGV (Fundação Getúlio Vargas), membro efetivo e Diretor de Relações Institucionais do IASP, membro das Comissões de Processo Constitucional e Bioética do IASP, membro efetivo do Instituto dos Advogados Brasileiros (IAB), parecerista e consultor da revista do Conselho da Justiça Federal e Advogado.

E-mail: zgneto@uol.com.br.

Endereço profissional: Geraige Advogados Associados, Avenida 19, n. 19.073, Centro - 14789-300 - Barretos - SP.

Kerton Nascimento e Costa é mestrando em Direitos Coletivos e Cidadania pela UNAERP, bolsista CAPES e servidor público estadual. E-mail:kertoncosta@hotmail.com/kertoncosta@gmail.com.

Endereço profissional: Universidade de Rio Preto - Av. Costábile Romano, n. 2.201,, Ribeirania, Ribeirao Preto, SP - 14096-900. 